\title{
Top feed supplements is cheaper and sure shot reliable alternative to breastfeeding for elimination of mother to child transmission of HIV
}

\author{
Ajai Krishna Srivastava*, Manoj Tangri
}

Department of Obstetrics and Gynecology, Command Hospital (EC), Alipore Road, Kolkata, Bengal, India

Received: 14 June 2016

Accepted: 02 July 2016

\section{*Correspondence:}

Dr. Ajai Krishna Srivastava,

E-mail: ajaidoc@gmail.com

Copyright: ( $\odot$ the author(s), publisher and licensee Medip Academy. This is an open-access article distributed under the terms of the Creative Commons Attribution Non-Commercial License, which permits unrestricted non-commercial use, distribution, and reproduction in any medium, provided the original work is properly cited.

\section{ABSTRACT}

Background: To find the perinatal outcome in HIV positive mothers without allowing breastfeeding.

Methods: In this study all antenatal women attending our hospital OPD were screened for HIV. All HIV positive women were administered ARV prophylaxis. The method of delivery was based on the viral load in third trimester. The infants were administered NVP at birth and ZDV for six weeks. All mothers were taught the significance of infant top feeding method and were given formula feed procured by the hospital for first six months. DNA PCR screened all infants for HIV infection at 6 weeks and 6 months. They underwent HIV antibody testing by ELISA at 18 months.

Results: 5701 pregnant women were screened for HIV infection from Nov 2002 to Aug 2014. 152 women were found positive for infection. 127 seropositive women delivered with us. All were administered ARV. Those who delivered with us were followed up during their pregnancy with CD4 count, viral load. All women with viral load higher than cut off women were delivered by caesarean section. All mothers were educated and provided for top feed and no children were permitted breastfeeding. They were given Nevirapine at birth and Zidovudine for 6 weeks. We found only one child positive for HIV infection out of 127 tested till the age of six months. There was no neonatal or infant mortality and significant morbidity from other infectious diseases.

Conclusions: MTCT programme can lead to elimination of vertical transfer of HIV infection from mother to child even in lower socio economic class if they were provided supplementary feeds from healthcare resources along with other interventions. It is cheaper than administering ART to newborn and the mother for six months.

Keywords: HIV in Pregnancy, MTCT, Breastfeeding

\section{INTRODUCTION}

Acquired immunodeficiency syndrome (AIDS) was first described in 1981 when a cluster of patients was found to have decreased immunity and Pneumocystis jiroveci pneumonia. ${ }^{1}$ It was estimated in 2012 that there were 35.3 million infected persons with HIV/AIDS worldwide; 2.3 million new cases of HIV infection; and 1.6 million HIVrelated deaths. ${ }^{2}$

In the United States through 2006, the Centers for Disease Control and Prevention (2008b) estimated that there were 1.1 million infected individuals and almost a half million deaths. In 2006, women accounted for 26 percent of all HIV/AIDS cases among adults and adolescents, the vast majority of which resulted from heterosexual contact. ${ }^{3}$

The estimated number of perinatally transferred HIV infection cases had decreased radically over the last two decades in the US. ${ }^{4}$ This is predominantly due to the implementation of universal antenatal HIV screening with ART given to the pregnant woman and to her neonate. Moreover, HAART administration has led to a much higher number of people living much longer with chronic HIV infection. ${ }^{5}$ 
For obstetricians, prevention of MTCT in HIV infected pregnant women is the main challenge.

The World Health Organization has promoted a comprehensive approach to preventing MTCT. This includes four components:

(1) Primary prevention of HIV infection.

(2) Prevention of unintended pregnancies among HIVinfected women.

(3) Prevention of HIV transmission from HIV-infected mothers to their infants.

(4) Care, treatment and support for HIV-infected mothers, their children and families. All four of these have a role to play in preventing MTCT and optimizing care of HIV-positive women and their children. Counseling, testing and the identification of HIV-positive women is essential to provide the most appropriate care; CD4+ cell counts form a critical link between antenatal care and antiretroviral therapy (ART) services, especially for asymptomatic women.

The transmission of HIV from mother to child is maximum during last few weeks and delivery. However a significant vertical transmission takes place during breastfeeding.

Transmission rates for breast feeding may be as high as 30 to 40 percent and are associated with systemic HIV viral burden. ${ }^{6,7}$ The WHO recommends no breastfeeding in HIV positive mothers in high resource countries. In third world countries however, the recommendations are that breastfeeding should be promoted as alternative top feeds. It is feared that lack of breastfeeding may be more detrimental to the newborn and make the child more prone to infections than the chances of HIV infection. ${ }^{8}$

This study was designed to evaluate the outcome of children from the lower socioeconomic class with no breastfeeding and follow them till one and half year to find out if they would have any adverse impact.

Aim of the study was to find the perinatal outcome in HIV positive mothers without allowing breastfeeding.

\section{METHODS}

This study was carried out at a tertiary Hospital at Pune.

In this study all antenatal women attending our hospital OPD were screened for HIV. All HIV positive women were administered ARV prophylaxis. The method of delivery was based on the viral load in third trimester. The infants were administered NVP at birth and ZDV for six weeks. All mothers were taught the significance of infant top feeding method and were given formula feed procured by the hospital for first six months.
DNA PCR screened all infants for HIV infection at 6 weeks and 6 months. They underwent HIV antibody testing by ELISA at 18 months.

\section{RESULTS}

5701 pregnant women were screened for HIV infection from Nov 2002 to Aug 2014. 152 women were found positive for infection. 127 HIV seropositive women delivered with us.

Table 1: Prevalence of HIV infection.

\begin{tabular}{|ll|}
\hline $\begin{array}{l}\text { No of pregnant women } \\
\text { screened for HIV }\end{array}$ & No of women positive \\
\hline 5701 & for HIV \\
\hline
\end{tabular}

The subjects were ranging from 18 to 38 years' age and maximum between 22 and 28 years. They belonged to social class III and IV. All were administered ARV HAART with three drug combination of Zidovudine, Nelfinavir and Efavirenz starting from 14 to 20 weeks' gestation depending upon the period of pregnancy when they were diagnosed. Those who were booked with us were followed up during their pregnancy with CD4 count, viral load.

Table 2: Delivery of HIV seropositive mothers.

\begin{tabular}{|lll|}
\hline $\begin{array}{l}\text { No of women } \\
\text { positive for } \\
\text { HIV }\end{array}$ & $\begin{array}{l}\text { No of women } \\
\text { with early } \\
\text { pregnancy loss }\end{array}$ & $\begin{array}{l}\text { No of HIV } \\
\text { positive } \\
\text { women } \\
\text { delivered }\end{array}$ \\
\hline 152 & 17 & 127 \\
\hline
\end{tabular}

All women with viral load higher than cut off, i.e. 1000 copies per $\mathrm{ml}$ were delivered by elective caesarean section. The cutoff of viral load for caesarean section after 2010 was brought down to above 400 copies per ml. We had 103 caesarean sections and 24 vaginal deliveries. During caesarean section, the membranes were aimed not to be ruptured till the head of the baby was delivered out of the uterine incision.

The mothers who were delivered vaginally also had strict precautions during labour to prevent vertical transmission during delivery.

During labour, their amniotic membranes were not ruptured, instrumental deliveries were avoided as far as possible, and no patients were subjected to scalp blood sampling. Routine ORO nasal suction was avoided in all neonates. All mothers were educated and provided for top feed and no children were permitted breastfeeding. They were given tablet cabergoline for suppression of milk secretion after delivery. There were no cases of breast abscess or mastitis.

Neonates were administered three boxes of $1 \mathrm{~kg}$ formula feed per month for the first two months, four boxes for 
the next two months and five boxes for the next two months under close guidance. The children were weaned to other food articles after six months' age. They were given Syp Nevirapine at birth and Syp Zidovudine for 6 weeks.

All children were tested for HIV infection at one-week age by HIV RNA PCR, DNA PCR again at 6 months.

We found only one child positive for HIV infection out of 127 tested till the age of six months. The mother of this child came to us at 34 weeks and delivered at 36 weeks and had only ten days of ARV therapy. She had a viral load of 3421 copies per ml. Probably it was inadequate exposure of ARV in this woman which led to higher viral load and subsequent MTCT.

There was no neonatal or infant mortality and significant morbidity from other infectious diseases.

\section{DISCUSSION}

The paediatric HIV infection is deadlier than adult infection. The progression of the disease is more rapid and prognosis is poorer. Majority of paediatric HIV infection; $95 \%$ comes from vertical transmission. If no interventions are done to prevent MTCT, it is estimated that 25 to $40 \%$ women will transmit their HIV infection to the offspring during pregnancy and delivery. If no precautions are taken during breastfeeding time, approximately another $15 \%$ children will get infected taking the tally of vertical transmission to approximately $40 \%$. If all precautions are taken, the vertical transmission of HIV from mother to child can be brought below $2 \%$.

The safety precautions and measures advocated to prevent MTCT are same for developed countries as third world countries during antenatal period and delivery. However, we as caregivers must decide on all aspects of precautions to prevent MTCT.

In developed countries, the HIV carrier women are universally advised not to breastfeed their children to decrease the chances of post natal MTCT. In developing countries however, it is thought that lack of breastfeeding will make these children more exposed and susceptible to other respiratory and GIT infections, which in itself increase the mortality and morbidity in these children.

In our study, we decided to test the possibility of having no breast-feeding to the children born to HIV positive mothers and providing them free formula feed supplements. There was one team of obstetrician, counselor and three residents of the Obstetrics and Gynecology who were coordinating the care of these women. The availability of ARV drugs for mothers and neonates was ensured.

The mothers were motivated on every visit and the various steps of prevention of MTCT and given health education about not giving breastfeeds to their neonates after delivery. With single dedicated team of healthcare providers, we were able to motivate and convince the mothers to not breastfeed their children.

The children after delivery were under care of a single paediatric specialist with interest in HIV infection. The ARV prophylaxis, top feed health and weaning education and monitoring of presence or absence of infections was done by single paediatric specialist and his team.

We found that the result of our intervention nearly eliminated the MTCT in all mothers but one who enrolled late with us. We found that the supplementation of top feed was simpler and costlier than providing ARV to the mother for six months breastfeeding period.

In our study, the rate of vertical transmission of HIV from mother to child was less than $1 \%$ and we had no significant maternal or neonatal morbidity despite no breastfeeding.

\section{CONCLUSION}

MTCT programme can lead to elimination of vertical transfer of HIV infection from mother to child even in lower socio economic class also if they were provided supplementary feeds from healthcare resources along with other interventions. It is cheaper than administering ART to newborn and the mother for six months. Even in lower socioeconomic class, if adequate health education is imparted, supplemental feeds are provided and adequate interventions are done, MTCT can surely be eliminated.

Funding: No funding sources

Conflict of interest: None declared

Ethical approval: The study was approved by the Institutional Ethics Committee

\section{REFERENCES}

1. Gallo RC, Montagnier L. The discovery of HIV as the cause of AIDS. N Engl J Med. 2003;349:2283.

2. UNAIDS: Global Report: UNAIDS report on the global AIDS epidemic. Available at: http://unaids.org/en/media/unaids/contentassets/docu ments/epidemiology/2013/gr2013/UNAIDS_Global_ Report_2013_en.pdf.

3. Centers for disease control and prevention: HIV/AIDS surveillance report. Cases of HIV infection and AIDS in the United States and Dependent Areas. 2006;18:1.

4. Centers for disease control and prevention: AIDS surveillance trends, slide set. 2011. Available at: http://www.cdc.gov/hiv/pdf/statistics_surveillance_2 010aidstrends.pdf.

5. Fenton KA: Changing epidemiology of HIV/AIDS in the United States: Implications for enhancing and 
promoting HIV testing strategies. Clin Infect Dis. 2007;45:S213.

6. Kourtis AP, Jamieson DJ, de Vincenzi I. Prevention of human immunodeficiency virus-1 transmission to the infant through breastfeeding: new developments. Am J Obstet Gynecol. 2007;197:S113.

7. Slyker JA, Chung MH, Lehman DA. Incidence and correlates of HIV-1RNA detection in the breast milk of women receiving HAART for the prevention of HIV-1 transmission. PLoS ONE. 2012;7(1):e29777.

8. World Health Organization: Guidelines on HIV and infant feeding. Principles and recommendations for infant feeding in the context of HIV and a summary of evidence. Geneva, WHO Press, 2010.

Cite this article as: Srivastava AK, Tangri M. Top feed supplements is cheaper and sure shot reliable alternative to breastfeeding for elimination of mother to child transmission of HIV. Int J Reprod

Contracept Obstet Gynecol 2016;5:2709-12. 